\title{
A INDÚSTRIA CULTURAL COMO OBJETO DE PESQUISA GEOGRÁFICA
}

\section{Rodrigo Ramos Hospodar Felippe Valverde ${ }^{1}$}

Resumo: Há na atualidade uma grande confusão a respeito do significado da noção de indústria cultural e dos seus possiveis interesses de estudos em diferentes ciências sociais. Através desse artigo, queremos encontrar elementos que nos permitam discutir princípios gerais para a criação de modelos aplicáveis a estudos nesse tema de pesquisa geográfica. Para tanto, é preciso mais uma vez realizar uma análise das conexões entre as dimensões econômica e cultural, tentando superar a tendência à dicotomia que costuma ser dominante no contexto do conhecimento geográfico. Ao fazê-lo, oferecemos reflexões que nos auxiliam a compreender as diferentes mudanças nos processos produtivos, nos ativismos sociais, nas formas urbanas e nos clamores por autonomias que observamos no mundo globalizado.

Palavras-chave: Indústria Cultural, Espaço, Modelos.

\section{CULTURAL INDUSTRY AS SUBJECT OF GEOGRAPHICAL RESEARCH}

Abstract: Currently, there is a great confusion about the meaning of the notion of cultural industry and its possible interests to different social sciences. Through this article, I want to find out the elements that could allow us to discuss general principles for creating frameworks applicable in geographic research. In order to do so, it is needed to evaluate once more the connections between the cultural and economic dimensions, trying to bypass the dichotomic tendencies that are usually dominant within the geographical knowledge. I offer as part of the results a set of situations that aid us to comprehend the changes in the productive processes, social activisms, urban morphology and autonomy claims that are visible in the global society.

Key words: Cultural Industry, Space, Frameworks.

\section{INTRODUÇÃO}

O termo indústria cultural indica um conjunto diverso de objetos de investigação que pode confundir os cientistas sociais: por vezes sua ideia expressa o modelo teórico da dominação social via manipulação das artes e das comunicações (ADORNO, 2002); em outros casos, se refere à exploração econômica de produtos voltados para o entretenimento e para a troca de informações, como livros, jornais, revistas, moda, cinema, videogames, música e cultura urbana (KONG; GIBSON, 2005); há ainda quem associe sua ideia à difusão de valores através de produtos, na medida em que qualquer atividade produtiva atual se constrói também

1. Professor Doutor do Departamento de Geografia, Universidade de São Paulo (rvalverde@usp.br). 
através de um referenciamento cultural que o qualifica (GERTLER, 2010; VALVERDE, 2010). Porém, a confusão entre tais elementos não pode ser entendida como desinteresse na sua discussão. Acreditamos, inclusive, que tal confusão pode ser importante para que se compreendam as características de diversos modelos diferentes de operacionalização de indústrias culturais no mundo contemporâneo.

$\mathrm{Na}$ atualidade, não apenas os grandes agentes econômicos já descobriram as vantagens de um referenciamento cultural de seus mais diversos produtos, como por exemplo, os Estados já aceitaram que é preciso pensar na cultura como via importante para o desenvolvimento regional, assim como os agentes do terceiro setor já tomaram práticas culturais como formas de intervenção econômica e política sobre o mundo. Por mais impreciso que seja o próprio estatuto ontológico da cultura, é preciso reconhecera força de sua ideia geral para o mundo real. Nesse contexto, (re)produzir cultura significaria promover intervenções no mundo que são significativas, uma vez que ultrapassam a questão da identidade e do consumo. Pensar, agir e produzir sob a justificativa cultural significaria realizar a escolha de uma estratégia que pode aproximar agentes, mobilizar recursos e ganhar nova força no mundo globalizado.

Nosso objetivo geral é oferecer um quadro panorâmico de uma noção presente no debate da teoria social de forma ampla, mas que, em grande parte, se mostrou distante do debate da Geografia. Nesse processo, enquanto sociólogos, filósofos e economistas (entre outros profissionais) discutiam o valor econômico da cultura e os efeitos da massificação na sociedade, os geógrafos deixavam de pensar nos possíveis efeitos e qualificações que as categorias espaciais poderiam oferecer a esse debate. Para reverter esse quadro, é preciso igualmente sugerir, de forma mais específica, como a Geografia pode orientar linhas de estudos que explorem o quadro de discussão das indústrias culturais através de temas e abordagens que Ihe são caras. Como sugeriu Castree:

I suggest an alternative research agenda for those interested in economyculture relations (and, for that matter, those economic and cultural geographers who are not). This agenda entails close scrutiny of how and why the meanings of the terms economy and culture are 'fixed' so that they appear to have stable ontological referents. It is an agenda that applies, auto-critically, to geographers themselves. To the extent that economic and cultural geographers create knowledge about economy and culture, they 
must interrogate their own ideational creations, as much as those that are fashioned, circulated and contested by real-world actors (2004: p.210).

Para tanto, é preciso fazer frente à oposição de cunho teórico-metodológico que se constituiu entre abordagens culturais e econômicas, representada aqui pelos trabalhos de Jackson e Cosgrove e de Mitchell. Os dois primeiros autores afirmam que a cultura seria: "the medium through which people transform the mundane phenomenon of the material world into a world of significant symbols to which they give meaning and attach value" (COSGROVE; JACKSON,1987, p. 99). Por derivação, a ideia de cultura seria particularmente forte quando comparada a outros domínios da vida social. Tal ideia trataria de um sistema composto por diferentes significados, relativo ao processo de comunicação, de aprendizado e passível de transformações, antes mesmo que uma forma mais material e objetiva pudesse se construir em cada indivíduo. Para Jackson e Cosgrove, a cultura possuiria um estatuto ontológico anterior aquele da economia e conferiria diferentes significados ao mundo real.

Em resposta, Mitchell define a cultura da seguinte maneira: “[...] there is no such (ontological) thing as culture. (...) the very idea of culture has been developed and deployed as a means of attempting to order, control and define 'others' in the name of power or profit" (2000: p.103-104).Vemos que sua percepção estabelece outra cadeia de valores, na qual a cultura seria apenas uma ideia, mas não possuiria qualquer sentido concreto em si mesma. Para Mitchell, o mundo real poderia ser melhor estudado por intermédio das trocas econômicas, dos seus fundamentos ideais e de suas consequências políticas. O autor considera a ideia de cultura apenas como uma estratégia para influenciar comportamentos e qualificar dominações, tendo o seu princípio, o seu meio e o seu fim expressos através de outros estatutos ontológicos (economia e política).

Acreditamos que os termos pelos quais essa discussão foi realizada nos levavam ao empobrecimento das relações entre economia e cultura. Como Hartshorne (1939) colocava no século passado, o objetivo da Geografia deveria compreender e explicar o mundo real, sem presumir que um único modelo abstrato serviria de fundamento para todos os seus estudos empíricos. Da forma como essa discussão se desdobrou dentro da Geografia, os objetivos da discussão de cultura estariam mais ligados às disputas pelas teorias hegemônicas dentro das universidades inglesas e americanas do que propriamente a nossa 
capacidade como profissionais de compreender e explicar os fenômenos socioterritoriais das indústrias culturais.

Para ultrapassar esses limites, definimos o seguinte conjunto de etapas para o desenvolvimento desse artigo: primeiro, faremos a discussão da origem da noção de indústria cultural na Escola de Frankfurt e dos seus possíveis interesses para as discussões da Geografia; em segundo lugar, demonstraremos que o interesse dessa noção de indústria cultural para a Geografia pode ser melhor compreendido através da conexão que realiza entre economia e cultura, rompendo uma tradição de isolamentos que foi dominante na Geografia por um longo período; a definição de possíveis elementos para modelos de desenvolvimento de estudos geográficos das indústrias culturais se apresenta então como a terceira etapa desse artigo.

\section{MÉTODO}

A indústria cultural se tornou um tema de investigação das ciências sociais através da obra de Theodor Adorno e de seus colegas da Escola de Frankfurt. Esse autor considerava que a objetificação da cultura em valor econômico trazia uma série de consequências para a sociedade. A primeira e mais importante dessas consequências seria encontrada através de um discurso único, de forte carga ideológica. Adorno se referia ao fato de que, no final do século XIX e no início do século XX, se descobriu a importância da cultura para viabilizar projetos econômicos e políticos. Dessa forma, o autor avaliava que a cultura passou a ser reconhecida como um elemento estratégico para garantir a filiação dos indivíduos ao projeto nacional e aos seus circuitos econômicos. De acordo com Adorno e Horckeiheimer:

A unidade sem preconceitos da indústria cultural atesta a unidade em formação da política. Distinções enfáticas, como entre filmes de classe A e $B$, ou entre histórias em revistas de diferentes preços, não são tão fundadas na realidade, quanto, antes, servem para classificar e organizar os consumidores a fim de padronizá-los. Para todos alguma coisa é prevista, a fim de que nenhum possa escapar; as diferenças vêm cunhadas e difundidas artificialmente (2002: p.7).

É nesse contexto que Adorno e Horckeiheimer enxergavam a formação de um sistema cultural controlado, absolutamente negativo para o indivíduo e para a diversidade social. Nesse sistema, seria possível enxergar um esvaziamento do sentido da vida social dentro da modernidade que seria promovido pela substituição dos valores tradicionais por produtores 
e valores produzidos por acordos mais ou menos formais entre o Estado e os agentes privados. Para os autores, esse seria um processo consciente e intencional que não deveria ser confundido de forma alguma com um mundo no qual se criariam múltiplas representações culturais livres de um poder. Para o autor, se os princípios culturais não mais respondiam tão prontamente aos valores religiosos ou as práticas tradicionais, caberiam ao Estado e a iniciativa privada ocupar de forma ativa esse vácuo de poder. Em suas palavras:

A tese sociológica de que a perda de apoio na religião objetiva, a dissolução dos últimos resíduos pré-capitalistas, a diferenciação técnica e social e a extrema especialização deram lugar a um caos cultural é cotidianamente desmentida pelos fatos. A cultura contemporânea a tudo confere um ar de semelhança. Filmes, rádio e semanários constituem um sistema. Cada setor se harmoniza em si e todos entre si (2002: p.5).

Ainda segundo o autor, o controle do consumo das formas culturais pelos grandes agentes econômicos e políticos esvazia a representação artística e popular de seus sentidos originais. Para Adorno, no momento em que deixaria de ser matéria exclusiva dos grupos tradicionais, com suas territorialidades restritas, e ganharia publicidade, a cultura passaria a ser vista como sinônimo de manipulação e seleção realizada pelos poderes econômico e político. Notaria-se assim um claro enfraquecimento da cultura popular e um relativo controle da sua manifestação, pois aquelas representações que fossem consideradas inadequadas poderiam ser marginalizadas. O processo de renovação cultural garantiria assim que apenas aquelas referências consideradas positivas ao projeto nacional teriam lugar no futuro.

No que tange ao interesse da Geografia pelas ideias de Adorno, a indústria cultural caracterizaria um processo de homogeneização do espaço que facilitaria a dominação econômica e política da sociedade. O aperfeiçoamento das técnicas de comunicação e a ampliação das tarefas do Estado, envolvendo o princípio da construção da nacionalidade, deveriam se tornar etapas complementares. Para que isso ganhasse maior eficácia, seria preciso conferir visibilidade e, para tanto, materialidade no espaço. A ideia de indústria cultural apresentaria então configurações técnicas ao espaço que seriam definidas por altos círculos político-econômicos, com capacidades decisórias que permitiriam maior controle sobre as formas e maior previsibilidade em relação aos comportamentos que essas sugeririam. 
Nas palavras dos autores, junto às mudanças que se desenvolvem no espaço físico, se observariam alterações de comportamento. A força da linha de argumentação se encontraria em um limite de pensamento que só pode ser identificado como determinista, ainda que este estivesse mais conectado a discussão da tecnologia e do Estado do que as suas bases espaciais. Mais precisamente, Adorno e Horckeiheimer propunham que esse processo se refletiria na perda do livre-arbítrio e no esvaziamento da autenticidade. Se houve um momento na história em que a cultura tivesse representado uma vivência cotidiana e popular, esse momento teria sido substituído por outro, no qual se parte do pressuposto de que a cultura foi criada em escritórios, valorizada pelo trabalho técnico e massificada para se tornar apta a todo e qualquer indivíduo com o mínimo de esforço intelectual. Nas palavras dos autores:

Senso crítico e competência são banidos como presunções de quem se crê superior aos outros, enquanto a cultura, democrática, reparte seus privilégios entre todos. Diante da trégua ideológica, o conformismo dos consumidores, assim como a imprudência da produção que estes mantêm em vida, adquire uma boa consciência. Ele se satisfaz com a reprodução do sempre igual. A mesmice também regula a relação com o passado. A novidade do estágio da cultura de massa em face do liberalismo tardio está na exclusão do novo. Nada deve permanecer como era, tudo deve continuamente fluir, estar em movimento. Pois só o triunfo universal do ritmo de produção e de reprodução mecânica garante que nada mude, que nada surja que não possa ser enquadrado. Acréscimos ao inventário cultural já comprovado são perigosos e arriscados (2002: p.17).

Para tanto, rádios, jornais e cinema cumpririam etapas importantes desse processo de dominação do território. As informações, ideias, valores e eventos propagados seriam selecionados de forma a facilitar a dominação, diminuir o senso crítico e auxiliar o consumo. Se houvesse inicialmente maior variedade em seus projetos, focados em diferentes classes sociais e, por vezes, promovedores de certas qualidades de argumentação e desenvolvimento artístico, Adorno e Horckeiheimer argumentavam que os controles técnicos, a propaganda e a censura alterariam essa situação. Muito além de uma visão idealizada ou da simples representação de negócio de poderosas classes, Adorno enxerga um processo mais complexo por trás das suas difusões:

O cinema e o rádio não têm mais necessidade de serem empacotados como arte. A verdade de que nada são além de negócios lhes serve de ideologia. Esta deverá legitimar o lixo que produzem de propósito. $O$ cinema e o rádio se auto-definem como indústrias [...] A participação de milhões em tal indústria imporia métodos de reprodução que, por seu turno, fazem com 
que inevitavelmente, em numerosos locais, necessidades iguais sejam satisfeitas com produtos estandardizados. O contraste técnico entre poucos centros de produção e uma recepção difusa exigiria, por força das coisas, organização e planificação da parte dos detentores. Os clichês seriam causados pelas necessidades dos consumidores: por isso seriam aceitos sem oposição. Na realidade, é por causa desse círculo de manipulações e necessidades derivadas que a unidade do sistema torna-se cada vez mais impermeável. (2002: p.6).

De acordo com os autores, a cultura não seria nunca mais um produto social autêntico, realizado e vivido coletivamente e que tampouco era uma expressão individual, uma invenção genial que transformava. Para Adorno e Horckeiheimer, a cultura seria a partir de então um produto direto da indústria, dominado por poucos em seu conhecimento abstrato e em seu sentido específico, mas seus produtos e sua sensação de diversão seriam plenamente acessíveis. De acordo com essa visão, a cultura passaria a ser um produto técnico do mundo atual, imposto como parte de um processo de conversão de uma concepção geral de indivíduo em um consumidor passivo, incapaz de realizar escolhas. Seria realizada então uma separação fundamental entre os produtores de cultura e os seus consumidores, o que seria uma característica marcante de uma nova e definitiva forma de alienação, pois este seria o último campo de independência que parecia ter sido rompido. Em suas palavras:

[...] os habitantes afluem aos centros em busca de trabalho e de diversão, como produtores e consumidores, as unidades de construção se cristalizam sem solução de continuidade em complexos bem organizados. A unidade visível de macrocosmo e de microcosmo mostra aos homens o modelo de sua cultura: a falsa identidade do universal e do particular. Toda a cultura de massas em sistema de economia concentrada é idêntica, e o seu esqueleto, a armadura conceptual daquela, começa a delinear-se. Os dirigentes não estão mais tão interessados em escondê-la (2002: p.5).

O último elemento do modelo de indústria cultural tal qual foi proposto por Adorno é aquele que estabelece que não há qualquer via de saída prevista dentro dessa cadeia de dominação. Essa infalibilidade da dominação se revelaria na total desconstrução do ideal recém-criado da autoconsciência e do livre-arbítrio do indivíduo moderno. A indústria cultural estabelece uma influência estrutural sobre a sociedade através da massificação dos meios de comunicação, do trabalho, do ensino e das atividades de lazer. Nos limites do pensamento dos autores, é impossível uma resistência efetiva a tantos rigores técnicos - o convívio social que garantiria um mínimo de personalidade e de identidade de grupo seria também ditado desde as mais tenras idades. Nesse processo, toda a variabilidade de 
interpretações do mundo seria substituída pelo conformismo e pelo consumismo, que, necessariamente, impediriam o pensamento crítico, a mudança e a verdadeira democracia. Nos termos propostos, trocaríamos a habilidade crítica por um certo sentimento de satisfação trazido pelas representações culturais, sentimento este que seria manipulado diretamente. Para os autores, esse quadro pessimista se constrói pela:

[...] atrofia da imaginação e da espontaneidade do consumidor cultural de hoje não tem necessidade de ser explicada em termos psicológicos. Os próprios produtos, desde o mais típico, o filme sonoro, paralisam aquelas capacidades pela sua própria constituição objetiva. Eles são feitos de modo que a sua apreensão adequada exija, por um lado, rapidez de percepção, capacidade de observação e competência específica, e por outro é feita de modo a vetar, de fato, a atividade mental do espectador (2002: p.10).

Para os autores, tal força da indústria cultural se manteria mesmo no caso em que esse processo de enfraquecimento intelectual derivasse em uma postura irracional da parte dos consumidores. Nem mesmo possíveis instabilidades sociais e insatisfações não politizadas poderiam sabotar os efeitos das indústrias culturais modernas, diferenciando os limites da técnica no século XX em relação a outros períodos da história. Enquanto, para alguns, tal irracionalidade representaria o germe da mudança e da quebra da dominação pela dificuldade em se prever as formas e sentidos da irracionalidade, para Adorno e Horckeiheimer não se configura essa suposta solução. De fato, os autores contraargumentam no sentido de que a irracionalidade e o caos se tornam a própria estratégia e finalidade da cadeia produtiva de cultura. Através dos registros dessas pequenas dissonâncias, seria possível renovar o exercício da dominação sem perder o controle da estrutura. Seria possível rapidamente identificar, reduzir e padronizar tais representações caóticas antes de seu processo de politização. Em suas palavras:

Mesmo se a planificação do mecanismo por parte daqueles que manipulam os dados da indústria cultural seja imposta em virtude da própria força de uma sociedade que, não obstante toda racionalização, se mantém irracional, essa tendência fatal, passando pelas agências da indústria, transforma-se na intencionalidade astuta da própria indústria. Para o consumidor, não há mais nada a classificar que o esquematismo da produção já não tenha antecipadamente classificado. A arte sem sonho produzida para o povo realiza aquele idealismo sonhador que parecia exagerado ao idealismo crítico (2002: p.8).

Ainda que se reconheçam os exageros como parte inerente de qualquer modelo, a indústria cultural de Adorno parece ter se difundido em uma crítica geral das artes, da comunicação, 
da modernidade e do indivíduo moderno. Nós a usamos para questionar o controle das ideias, o poder econômico sobre as culturas, a alienação (ou falsa consciência), os efeitos da padronização e da tecnologia em geral, assim como o desenvolvimento do individualismo exacerbado nos séculos XX e XXI. Antes mesmo de analisar como cada caso se organiza e se justifica, já se denuncia a finalidade perversa do modelo de indústria cultural. Nesse quadro de modelagem, os símbolos e representações dos grandes agentes, relativos aos Estados e os conglomerados privados do setor de cultura e comunicação, parecem estabelecer as condições para o controle e diminuição da diversidade do mundo. Por derivação desse modelo, os espaços se tornariam progressivamente menos "contaminados" pelo tradicional e pela escala local, sintetizando assim as principais características dos efeitos da cultura sobre o espaço segundo esses limites intelectuais.

Tal modelo foi criticado ao longo do século XX devido a alguns dos seus limites cognitivos e também pelas lacunas na sua argumentação. Por exemplo, um certo grau de elitismo e de etnocentrismo foi observado em sua obra, que sugeriria uma "verdadeira e alta cultura" em oposição a visões mais relativistas. Porém, o que nos interessa de forma mais destacada para discutir a importância da indústria cultural para a Geografia seria uma crítica mais clara ao finalismo em sua obra. O finalismo e o pessimismo presentes na argumentação foram colocados em questão pelos seus críticos mais complacentes como um produto do pensamento de seu tempo, no qual o Estado-Nação assumia um caráter autoritário e interventor, em aliança com grandes grupos econômicos.

Entre os mais críticos a essa visão, se coloca o surgimento de culturas e economias mais ou menos independentes entre países- o que já convidava a um certo grau de diferenciação. Habermas (1987) afirmava que Adorno teria superestimado a instrumentalização da razão dentro da sociedade moderna e, consequentemente, tomado a tecnologia e a industrialização em si mesmas como causas de todos os males. Na perspectiva de Habermas, ao menos em teoria, seria possível reverter parte da alienação, do controle social ou da ação perversa do Estado através da recuperação e desenvolvimento dos fundamentos iluministas e democráticos.Entre outras etapas para que se alcançasse esse fim, seria preciso atribuir nova força política ao espaço nesse processo. Mais importante, seria preciso admitir que a História não seria encerrada pela introdução de um sistema técnico, não importando as qualidades deste. 
Com a derrubada de diversas barreiras políticas, comerciais e culturais entre países no final do século $X X$, o grau de controle sobre as sociedade parecia diminuir. O Estado forte, com amplas funções e interesse explícito em produzir e orientar representações da nacionalidade vem sendo substituído por um modelo menor em tamanho e mais compreensivo em relação às representações culturais diversas. As barreiras comerciais apresentam tendências à diminuição, aumentando o volume de trocas e diversificando os parceiros comerciais e os produtos. A redução dos debates ideológicos também tem estimulado novas configurações político-sociais, nas quais níveis locais e regionais de organização são alçados a um novo patamar decisório. Ainda que tais mudanças não garantam democracia e não representem a ascensão da justiça social como valor último, tais mudanças alteram o quadro de realização da economia e da cultura. Se ainda é possível apontar alguma utilidade à discussão de indústria cultural, é preciso adaptar as suas discussões ao novo contexto histórico. Breve, a indústria cultural parece se constituir em uma via de estudos que é significativa para compreender as novas conexões entre cultura e economia.

\section{RESULTADOS}

Tomamos como primeira tarefa desse artigo apresentar possíveis elementos para uma nova definição de indústrias culturais, servindo esta tanto para estudos da organização sócioterritorial de novas cadeias produtivas, quanto para ampliação de cenários representativos para a identificação, referenciamento e mobilização. Para tanto, se mostra necessário defender que a ideia de um amplo processo de uniformização técnica e de redução da capacidade crítica, ao ponto da total subordinação tal qual havia sido sugerido por Adorno, se mostra apenas um modelo de análise que, de forma geral, funciona além dos limites das questões fundamentais do conhecimento geográfico. A hipótese levantada aqui é aquela que sugere a existência de algumas lacunas no pensamento de Adorno, ao tomar certas políticas e práticas de produção do espaço que, em certo sentido, problematizam a reflexão sobre a definição clássica. Também se mostra necessário estimular o conhecimento geográfico a questionar certos consensos já formados sobre a oposição de cultura e economia por intermédio do espaço.

Isso significa dizer que, antes de qualquer julgamento de valor, a indústria cultural pode ser estudada como objeto da Geografia. Em diversos momentos, a forma como a economia 
capitalista se desenvolve espacialmente foi reduzida e simplificada por um discurso que, em sua origem, descarta as especificidades das suas formas de ação devido a uma crítica moral que ecoava os termos gerais do modelo da Escola de Frankfurt descrito anteriormente. Esse é o caso, por exemplo, das obras de Harvey (1993) e de Santos (2000), quando seus trabalhos se atêm a uma escala geral de análise que aborda a produção e o consumo como etapas universais, perfeitamente complementares e perversas de uma mesma cadeia. Santos, por exemplo, argumenta que a publicidade seria um instrumento usado pelos meios de produção da sociedade capitalista para tornar mais branda uma dominação, um controle, mas não analisa a forma pela qual esta é pensada espacialmente. Em suas palavras, os agentes econômicos "produzem o consumidor antes mesmo de produzir os produtos [...] $\mathrm{Na}$ cadeia causal, a chamada autonomia da produção cede lugar ao despotismo do consumo" (2000: p.48). Nesse processo descrito por Santos:

Estamos diante de um novo encantamento do mundo, no qual o discurso e a retórica são o princípio e o fim. Esse imperativo e essa onipresença da informação são insidiosos, já que a informação atual tem dois rostos, um pelo qual ela busca instruir, e um outro, pelo qual ela busca convencer. Esse é o trabalho da publicidade (2000: p.39).

David Harvey já havia contribuído anteriormente para esta mesma linha de argumentação encontrada na obra de Adorno e Horckeiheimer, ao refletir sobre as consequências da mercantilização do mundo contemporâneo. Nos seus termos, novamente, o mundo atual se constituiria em um simulacro técnico imposto sobre todos, que dependeria de uma manipulação do espaço físico (real ou representado) como parte de uma estratégia de dominação:

[...] por meio da experiência de tudo - comida, hábitos culinários, música, televisão, espetáculos e cinema -, hoje é possível vivenciar a geografia do mundo vicariamente, como um simulacro. $O$ entrelaçamento de simulacros da vida diária reúne no mesmo espaço e no mesmo tempo diferentes mundos (de mercadorias). Mas ele o faz de tal modo que oculta de maneira quase perfeita quaisquer vestígios de origem, dos processos de trabalhos que os produziram ou das relações sociais implicadas em sua produção (HARVEY, 1993: p.270-271).

Sem desprezar as contribuições anteriores, sugerimos que há uma Geografia que simplifica a sociedade quando confundimos espaços de consumo e a reprimenda moral de um suposto "espaço consumido". Nosso ponto de partida se associa à visão de Amin e Thrift (2000), que estabelece que a relativização do referencial teórico de uma racionalidade econômica 
absoluta não deve ser confundida com uma simplificação realizada através da cultura, na qual tudo se poderia explicar por um conjunto de valores e de significados que fosse anterior a qualquer discussão material. A mediação da cultura pode de alguma forma problematizar a produção, por vezes alterando o trabalho exercido, os preços cobrados, os tipos de consumidores e os espaços de representação. Os autores apresentam esse quadro da seguinte forma:

Despite the pervasive 'softening' of baseline assumptions whereby values and norms, non-linearity and emergence, irrationality and desire, collective preferences and social structures, can be counted among the rules of economic action and organization, matters cultural are either unproblematically folded into the social or thought of as separate from matters economic (Amin e Thrift, 2000: p.144).

Como afirmaram Amin e Thrift, os princípios e objetivos do sistema econômico ainda continuam funcionando segundo os mesmos fundamentos. Não há dúvidas de que essa atividade esteja conectada ao funcionamento de articulações produtivas capitalistas, ao mercado internacional, à divisão do trabalho ou a busca do lucro. Mesmo nos casos em que a indústria cultural se posicione favoravelmente à redefinição das relações entre produtores e consumidores, ou à realização de uma economia solidária, se observam conexões com técnicas, capitais, conhecimentos e valores que apenas reforçam o sistema, ao invés de substituí-lo. Isso significa dizer que os autores que procuram uma via estruturalmente diferente para o exercício da economia e da política não encontram na indústria cultural, tal qual esta foi definida por diferentes geógrafos, a base para os seus estudos. No entanto, ao observar que um grande conjunto de alterações foi realizado no processo operacional de produção, em paralelo as mudanças nas formas de se conferir valor aos produtos de sentido cultural, é possível identificar geografias que ainda são pouco conhecidas. Nas palavras de Amin e de Thrift:

The basic assumptions and rules of economic theorization have not been allowed to be corrupted by culture (let alone anything else) even if the tools of the trade, now based on complex models or simulations, are readily deployed to evaluate matters cultural such as happiness from an economic standpoint (AMIN ; THRIFT, 2000: 144).

Essa perspectiva foi igualmente desenvolvida por Scott e Power, pois também convida a pensar as ligações entre cultura e economia de forma diferente daquelas que se mostraram dominantes na Geografia. Tradicionalmente, a Geografia Econômica e a Geografia Cultural 
tendem a polarizar as discussões da economia da cultura. Vemos, de um lado, essa polarização nos apelos à força de um economicismo estrutural e universal, no qual nenhuma representação cultural específica se mostra relevante e tudo pode ser explicado pela habilidade de indústrias em medir, quantificar, criar poucos modelos e tornar previsível o consumo de produtos. Nesse discurso, os padrões de consumo poderiam ser controlados pela expressão de uma perfeita racionalidade técnica e convertidos em verdadeiras formas de redução da diversidade cultural do mundo. Em oposição, falaria-se de diversos sistemas culturais relativos às tradições, no qual se faz uma apologia das bases de um discurso relativista que pressupõe que as representações e a ação humana são anteriores e totalmente independentes da vida material. Nesse olhar, nenhuma racionalidade seria capaz de evitar um aprendizado de processos de significação que bloquearia boa parte da eficiência da padronização técnica.

Seguindo os limites propostos por essa polarização, cultura e economia parecem não possuir relações de troca e, até mesmo, viver em uma constante batalha pela definição de uma matriz intelectual que molda o mundo concreto. Ao contrário dessa perspectiva que opunha as formas de se realizar o trabalho dos geógrafos, Scott e Power afirmam que produzir bens culturais e referenciar a produção se mostram processos conectados nos quais os espaços são pensados e utilizados além dos limites do pensamento geográfico mais frequente. Em suas palavras: "the association between place and product in the cultural industries is often so strong that it constitutes a significant element of firms' successes on wider markets" (SCOTT; POWER, 2004: p. 7).

Autores como Leslie também já haviam evocado os méritos desse tipo de abordagem, ao discutir as formas pelas quais os realizadores de campanhas publicitárias (e de produção de cultura em geral) atribuem valores imateriais aos seus produtos finais, ao buscar novos laços entre produto e consumidor:

Advertisers attempt to construct a dialogue between themselves and consumers and deploy research in order to be more reflexive about the advertisements they produce. In recent years, there has been a transformation in the discourses of advertising research away from those described by Jon Goss, which involve a detached model of market surveillance (as in geodemographics). Methods of research such as focus groups and consumer ethnographies point towards an active collusion with consumers and incorporate greater consumer input in the meanings of 
commodities. There has been a shift from analyzing the spatial distribution of consumers in geodemographics to studying the values attached to locations and the way identities are tied to place (LESLIE, 1999: p.1443).

Segundo Scott e Power, a indústria cultural "is a reflection of the increasing convergence that is occurring in modern society between economic order on the one hand and systems of cultural expression on the other" (SCOTT; POWER, 2004: p.3). A convergência referida por Scott e Power é observada em diferentes atividades e em diferentes formas de realizá-las. De acordo com Pratt, tais indústrias culturais envolvem um amplo conjunto de atividades, referentes à moda, aos esportes, aos comportamentos, à comunicação, à tecnologia, ao artesanato, às artes em geral, ao patrimônio, que têm como características em comum o fato de estabelecerem práticas colaborativas baseadas em valores e ideias que buscam no espaço uma parte importante para a sua significação. Não é mais suficiente reconhecer o avanço técnico em um produto, pois a competição e a ascensão de valores para o centro do debate da economia e da política alteram as possibilidades. Nas palavras de Pratt: "new technologies create the possibilities of new strategies, and also ofthe new economic objects that can be exploited and governed in their different ways" (2000: p.7).

Scott e Power também percebiam as diferenças do novo período e as qualificavam. De um lado, apontavam para o sentido da atribuição de valores culturais na atividade produtiva monopolística da Nova Economia: "The increasing importance of cultural and symbolic content in contemporary patterns of consumption means that monopolistic competition has become an ever more feasible option for firms throughout the new economy" (SCOTT; POWER, 2004: p.6). Ao fazê-lo, os autores argumentavam que a ampliação do comércio mundial poderia significar, por exemplo, que as privatizações e fusões de cadeias de telecomunicação levariam à hierarquização e, por consequência, isso poderia se refletir sobre o espaço em diferentes escalas. Ainda que isso possa ser explicado através do modelo da Escola de Frankfurt, é preciso considerar que a ampliação do espaço de representação, a diversificação do público-alvo e a variação nas fontes de dados exigem necessariamente alterações. Poderíamos enxergar o mesmo processo na moda, ou nos esportes, ou ainda em outras atividades. Por outro lado, os autores lembravam que os modos pelos quais tais novas indústrias culturais se realizavam eram sensivelmente distintos dos modelos do passado, utilizando novas práticas inspiradas em valores sociais ou comportamentos que ganhavam em importância no século XXI. Nem sempre a linha de montagem existente em 
multinacionais, tal qual se realizava dentro dos limites de um modelo fordista, seriam os mais adequados para exprimir a cadeia produtiva que conta com influências da ideia de cultura. Para os autores, os setores de pesquisa e desenvolvimento, marketing e de vendas de grandes empresas passam a contar variáveis que anteriormente eram afastadas pelo sentido subjetivo, pela intangibilidade ou pela conexão dessas ideias com propostas políticas (como acontece com o ambientalismo ou a responsabilidade social, por exemplo). É justamente nesse sentido que os autores argumentam que:

[...] cultural-products industries are growing rapidly; they tend (though not always) to be environmentally -friendly; and they frequently (though again not always) employ high-skill, high-wage, creative workers. Culturalproducts industries also generate positive externalities in so far as they contribute to the quality of life in the places where they congregate and enhance the image and prestige of the local area (SCOTT ; POWER, 2004: p.8).

Um terceiro aspecto que chama atenção na obra de Scott e Power é o fato de permitir usos e significações variadas para a discussão das indústrias culturais. Nesse processo, toma-se que a competitividade do mercado internacional estimula tal variedade de formas, o desenvolvimento de um novo ciclo de políticas culturais nacionais e plurinacionais (via blocos político-econômicos) multiplica e legitima seus arranjos possíveis, e até mesmo as ações de novos agentes que buscam vias para um desenvolvimento socioeconômico alternativo passam necessariamente pela sua reflexão. A uniformização técnica ou um único padrão de consumo não são mais perseguidos como obsessões: é possível conquistar novos segmentos populacionais e ampliar o valor dos produtos e/ou ideias através de diferenciais produtivos. Nesse processo, em parte, agentes focados em atividades econômicas e políticas se mostram igualmente interessados nas qualificações que a cultura pode trazer aos seus objetivos. As indústrias culturais se constituiriam então em verdadeiras estratégias para garantir maior difusão e adesão a valores e/ou a produtos. Nesse sentido, Scott e Power revelam que:

[...] a number of low and middle-income countries are finding that they too are able to participate in various ways in the new cultural economy, sometimes on the basis of traditional industries and cultures. (...) an accelerating convergence between the economic and the cultural is currently occurring in modern life, and is bringing in its train new kinds of urban and regional outcomes and opening up new opportunities for policymakers to raise local levels of income, employment and social well-being (2004: p.10). 
Tais posições parecem ecoar posições políticas e econômicas desenvolvidas recentemente na América Latina, entre outras localidades. Há hoje uma renovação de planos de desenvolvimento cultural com bases territoriais no Chile, na Argentina, no Brasil e na Bolívia. Por exemplo, o Plano Nacional para o Desenvolvimento da Bolívia prevê uma discussão de que as diferentes práticas culturais existentes no país devem servir a fins que são econômicos. O reconhecimento das matrizes identitárias não limitaria assim o interesse público na cultura e permitiria o desenvolvimento de diferentes indústrias culturais, capazes de transformar e integrar as tradições. O que antes simbolizava o atraso, a desconexão com o mundo moderno, parece hoje ser a via de acesso preferencial a "outra globalização". Nessa "outra globalização", a entrada nos circuitos comerciais deve ser acompanhada de uma finalidade política que pode dotar grupos étnicos tradicionais de poder decisório diante da força dos agentes globais. De acordo com o texto:

[...] se formalizarán espacios de encuentro conlos diferentes actores culturales en el nivel nacional, pueblos originarios, organizaciones populares y contemporáneas, con la creación de la Asamblea de las Culturas, para trabajar en forma interdisciplinaria e intersectorial en la recuperación de sus conocimientos, saberes, manifestaciones y expresiones que permita establecer referentes identitarios para que nuestras culturas se reconozcan y se diferencien. Además, para promover y dinamizar las economías en las comunidades, a través de la industria del turismo, la producción artesanal, el fortalecimiento de las pequeñas y micro empresas; constituyéndose en motores activos de la economía nacional. El sector cultural se constituirá en un instrumento de integración y encuentro, rompiendo con la apatía, intolerancia y el peligro de desintegración de nuestro país, abriendo espacios entre sectores públicos y privados (BOLIVIA, 2006: p.69).

Por último, o trabalho de Scott e Power pressupõe que a economia do conhecimento, organizada em redes de comunicação e mal regulada por sistemas nacionais e internacionais de direitos autorais, indica novas cadeias produtivas e oportunidades. Nas palavras de Scott: "Capitalism moves into a phase, where physical forms and their meanings are becoming more important and even dominant" (1997: p. 323). Negar a sua importância significa fechar os olhos para uma atividade produtiva que opera com sustentabilidade, localização, trabalho, velocidade de fluxos que são diferentes dos modelos clássicos fordista e toyotista. Também nota-se que o esquecimento desse mercado cultural indica o vício em se subordinar de forma equivocada uma parcela crescente do PIB e do conhecimento aos limites do conhecimento técnico e da política. Somos tributários da contribuição 
estabelecida por Scott e Power quando estes sugerem que tais conhecimentos e valores ligados à economia da cultura se mostram como diferenciais para avaliar a excepcionalidade da influência americana e japonesa sobre o mundo, por exemplo. Por derivação, qualquer modelo de relativização ou de rompimento dessa influência econômica e cultural pressupõe o amplo reconhecimento de como suas cadeias produtivas se realizam.

Nesse processo, as formas espaciais da economia da cultura precisam de novos modelos geográficos que ultrapassem a simples referência ao imperialismo cultural norte-americano ou europeu, ou ao peso de uma única tecnologia para a hierarquização do mundo. Por diferentes vias, é possível encontrar trabalhos geográficos referentes às indústrias culturais, entendidas como diferentes combinações de esforços de agentes públicos e privados no qual as formas, processos e ideias mais constantemente referenciadas pelos modelos de padronização encontrados no fordismo e no toyotismo passariam por modificações através da introdução de novas bases culturais, com diferentes resultados possíveis. Por vezes, esse processo se constituiria no fortalecimento de um processo de costumização, ao refletir valores que dialogam com a escala local e/ou regional. Em outros momentos, eles ganhariam uma dimensão transformadora do espaço, ao reordenar mais diretamente os seus elementos físicos e simbólicos (VALVERDE, 2010).

De uma forma geral, podemos encontrar a competição simultânea de múltiplos projetos por suas áreas de influência em um mundo que está significativamente mais aberto e que passa por transição de valores, de tecnologia e de lideranças. É a compreensão dessa variedade nos modelos espaciais das indústrias culturais que será desenvolvida no próximo item.

\section{Princípios para criação de modelos espaciais para as indústrias culturais}

O primeiro modelo de indústria cultural que chamamos atenção é aquele que pressupõe que o seu surgimento e difusão podem se caracterizar em um vetor de refuncionalização da cidade. Significa dizer que um certo grau de articulação e de concentração de agentes privados e públicos em uma área deteriorada da cidade podem ser reconhecidos como via de desenvolvimento. Nesse reconhecimento, é indicado que o poder municipal estimula a concentração de atividades, pois a indústria cultural muitas vezes não depende de grandes cadeias logísticas, de emissões de gases ou de amplas áreas para produzir. Com isso, as áreas periféricas do centro da cidade podem servir de base para a sua atividade produtiva. Antigos 
galpões, prédios abandonados, estacionamentos, bairros residenciais deteriorados, entre outras formas, podem rapidamente ser convertidos às novas finalidades, com preços relativamente baixos. Além disso, a área frequentemente já conta com amplos serviços, facilitando a implementação dos negócios.

Um exemplo amplamente divulgado desse tipo de indústria cultural pode ser observado na cidade de Montreal, Canadá. Atualmente, a cidade é reconhecida pela qualidade e diversidade de seu centro de produção multimídia (filmes, jogos de videogame, desenhos animados, entre outros). Mais importante do que a escala da produção ou a lucratividade do negócio foi a abertura de postos de trabalho de alto grau de formação na área central da cidade. Em um quadro de controle ambiental e de problemas para investimentos, se observava que a proximidade entre empresas do setor gerava uma sinergia que ultrapassava o limite da produção e se refletia no espaço. Tanto a iniciativa privada (através do mercado imobiliário ou da localização de novos empreendimentos de caráter subsidiário), quanto o poder público (através da abertura de linhas de crédito, de isenções de impostos, de city marketing, de bolsas de estudo e de redivisões funcionais) acompanharam esse movimento que nasceu limitado ao setor econômico (TREMBLAY; ROUSSEAU, 2005).

Para Tremblay e Rousseau, o processo observado na cidade de Montreal ainda está em curso e é necessário que a coordenação de ações públicas e privadas se torne mais eficiente e planejada. De acordo com os autores, as políticas públicas se desenvolveram por reação ao fenômeno começado por agentes privados, mas ainda é falha ao tentar organizar e dinamizar as atividades através de um planejamento mais extenso e focado. Ainda assim, o processo de concentração se mostra em curso no espaço da cidade:

[...] $90 \%$ of multimedia firms are in the Montreal region. More precisely, our own list of some 644 firms, developed within the ISRN project indicates that the multimedia sector in Montreal is strongly concentrated in a commercial zone composed of old industrial buildings, close to the centre of town, where a large number of smail firms are clustered. This is similar to what was observed in Vancouver and Toronto, where other authors observed a large number of small firms clustered in redesigned buildings close to downtown (Britton et Légaré 2004; Smith et al.2004). In Montreal, there appear to be two main clusters, according to our list of firms. They are largely concentrated on and around St-Laurence Boulevard, and in or around the Multimedia City (2005: p. 314). 
Para que essa refuncionalização possa ser bem-sucedida e duradoura em seu poder de crescimento econômico atrelado ao dinamismo urbano, é preciso evitar os trade-offs da competição. É fundamental que a disposição dessas empresas evite desperdícios, se escore na confiança mútua que viabilize a troca de parte dos conhecimentos e crie uma marca associada a essa parte da cidade, capaz, por si só, de atrair investidores e trabalhadores do mais alto grau de formação antes mesmo da discussão dos valores salariais, das condições de trabalho ou da equipe envolvida. Para tanto, Power e Scott enumeraram algumas características fundamentais que salientam as conexões entre agentes públicos e privados, características estas aplicáveis tanto a "cidade multimídia" de Montreal quanto a outras cidades que vivem oportunidades semelhantes:

Policy-makers thus need to pay attention to three main ways of promoting collective competitive advantage, which, on the basis of the modern theory of industrial districts can be identified as (a) the building of collaborative inter-firm relations in order to mobilize latent synergies, (b) the organization of efficient, high-skill local labor markets, and (c) the potentiation of local industrial creativity and innovation (SCOTT ; POWER, 2004: 9-10).

Um segundo modelo para a indústria cultural em nada reflete o anterior, pois pressupõe que a (re)produção de cultura é capaz de gerar mobilização política e, possivelmente, revalorização dos espaços. Nos referimos às iniciativas de mobilização social que dependem diretamente do poder de atração presente em atividades artísticas e ou esportivas. São ateliês, clubes, associações, teatros comunitários que convidam pessoas a participar de dinâmicas sócio-educativas que, de algum modo, permitem a redefinição de relações socioespaciais. Através do desenvolvimento mais ou menos formal de músicos e atletas, cria-se um ambiente no qual é possível minimizar os efeitos da fragmentação socioespacial e, nos casos de melhor funcionamento, intervir no espaço próximo de forma intensa. Nesse processo, o ativismo em questão poderia ser capaz de catalisar energias e demandas sociais em prol de uma causa maior, como, por exemplo, a mobilização política para se alcançar melhores condições de vida.

Consideramos esse tipo de ativismo uma forma particular de indústria cultural porque a finalidade política em sentido estrito não é nem o ponto de partida, nem o sentido da intervenção. Ainda que, de uma forma geral, a ação desse ativismo possa levar parte dos seus integrantes a agir coletivamente e se interessar por problemas públicos, não há 
nenhuma obrigação presente. Ao invés de defender de forma explícita um novo sistema socioeconômico, de participar regularmente de fóruns públicos, de integrar manifestações e partidos através da própria entidade, cabe a essa indústria cultural apenas permitir que uma parte das lacunas da formação da cidadania na sociedade moderna seja cumprida em outras localizações que não sejam as escolas, os partidos políticos ou outras instituições. Devido à lentidão destas instituições em incorporar causas mais atuais ou modificar suas formas de ação, autores como Sennett (1989) notaram o esvaziamento da esfera pública e de seus espaços. Para que tais causas ou ações encontrassem uma via de desenvolvimento que se desse independentemente das discussões ideológicas ou dos trâmites formais, seria necessário criar novos fóruns, mais restritos em suas discussões e mais ágeis em suas iniciativas. No entanto, o limite de mobilização dessa indústria cultural pode significar a integração de segmentos populacionais ao mesmo mercado de trabalho (juntamente aos seus valores) que indiretamente os havia excluído.

Um exemplo dessa prática seria o Grupo Cultural AfroReggae, que desenvolve trabalhos de integração de jovens em situação de vulnerabilidade social em diversas favelas da cidade do Rio de Janeiro. Seu objetivo seria o seguinte: "promover a inclusão e a justiça social, utilizando a arte, a cultura afro-brasileira e a educação como ferramentas para a criação de pontes que unam as diferenças e sirvam como alicerces para a sustentabilidade e o exercício da cidadania" (AFROREGGAE, 2012). Entre as dezenas de dinâmicas sociais diferentes, como aulas de grafite, música, dança, realização de vídeos, reciclagem, teatro, entre outras dinâmicas de grupo encontradas, o Grupo Cultural AfroReggae passa a ganhar mais do que uma importância local, pois seus produtos sociais são elevados à exposições e feiras internacionais, se constituindo em referências. De acordo com seus realizadores, busca-se: "borrar as fronteiras na cidade: norte e sul, favela e asfalto, preto e branco" (2012). As diferenças se tornam pretexto para o diálogo.São realizadas parcerias com instituições nacionais e internacionais no intuito de se alcançarem projetos de fomento econômico e atividades formativas que possibilitem melhor inserção no mercado de trabalho. Os jovens que passam por seus diversos núcleos e centros culturais são em parte desviados do caminho da violência do tráfico de drogas e, muitas vezes, introduzidos ao grande circuito artístico/cultural brasileiro ou, se possível, qualquer outro emprego do setor formal. Todo o ativismo é carregado de um sentimento de identidade territorial e de ações solidárias, mas, 
como tendência geral, se dá um fomento ao ordenamento social já conhecido, imbuídos dos problemas e vícios de um projeto hegemônico.

Outro modelo de estudo das indústrias culturais é aquele que sugere que a produção ou significação cultural pode promover alterações na rede urbana clássica. Corrêa (2006) define a rede urbana como a área de influência de uma cidade, que depende de variáveis: o acúmulo de capital, os centros de gestão, a população total, o parque industrial, entre outras possíveis. Normalmente, esse modelo clássico aponta para as capitais e cidades industriais como realizadoras ou coordenadoras de um conjunto de atividades que inexiste em cidades médias ou pequenas, garantindo os benefícios da centralidade.

Porém, no que tange à cultura, observa-se a possibilidade de se relativizar o peso da centralidade econômica, demográfica e/ou política, na medida em que, com investimentos seletivos e concentrados em atividades de produção e consumo de cultura, se estabeleça a inversão de fluxos em direção às cidades menores. Normalmente, esse movimento é referente ao setor e não necessariamente se traduz em uma quebra total da hierarquia, mas traduz uma significativa variação. Esse tem sido o caso, por exemplo, das cidades brasileiras de Paraty (Estado do Rio de Janeiro) e de Paulínia (Estado de São Paulo). Ambas, por diferentes iniciativas, tem apostado na produção e significação cultural como forma de atrair e concentrar recursos para suas cidades. Em Paulínia, cidade da Região Metropolitana de Campinas, se observa que uma parcela significativa do orçamento tem sido aplicada diretamente na criação de estruturas técnicas capazes de receber produtoras de cinema e eventos ou premiações culturais. Ao fazê-lo, dezenas de filmes utilizam as áreas da cidade e seus equipamentos e serviços (transportes, materiais, educação, catering etc.). Paralelamente, a iniciativa privada procura explorar as oportunidades, contratando mais gente e investindo mais do que em períodos anteriores.Paulínia se definiria a partir de então também como um polo de cultura:

Uma cidade só pode ser considerada um Polo - como somos no petróleo, por exemplo - se nela forem encontrados os elementos primordiais de parte de sua cadeia produtiva. E faltava esta visão na estratégia da política cultural de Paulínia.Como resultado, os filmes, que antes ficavam, em média, 03 (três) dias em nossa cidade, ficam agora, no mínimo 02 (duas) semanas e, no caso dos projetos que mais receberam aportes do Fundo Municipal de Cultura, espantosas 12 (doze) semanas. Quanto mais tempo em Paulínia, mais tempo para consumir e empregar gente de nossa 
cidade. Para estimular os gastos com empresas locais, a Secretaria de Cultura proibiu a realização de despesas com empresas cujo setor de atuação não estejam efetivamente instalados na cidade. Serviços como locação de equipamentos de vídeo/áudio/luzes (câmeras, luzes e outros) abriram espaço para setores como alimentação, transporte, técnicos, produtores e serviços gerais" (ALVES, 2009: p.4-5).

Ainda que se considere que não houve tempo para a realização de um balanço dessa prática diante da diminuição dos royalties do petróleo, do questionamento dos benefícios locais dos editais de cultura e dos seus efeitos duradouros sobre a prática do empreendedorismo na região, se coloca que, a curto prazo, os fluxos que compõem a rede urbana podem apresentar variação: um centro de peso econômico médio pode se mostrar como polarizador cultural.

Em quarto lugar, a indústria cultural pode ser constituída como uma tentativa de formalização da diversidade por intermédio da gestão do espaço. Procuram-se então os laços tradicionais desprezados pelo ritmo da vida moderna e procura-se de algum modo encontrar uma nova posição para as suas práticas. Seja através da mobilização cívica, seja por intermédio de um reconhecimento do valor subjetivo da representação cultural via política patrimonial, ou ainda pela descoberta do potencial turístico e/ou comercial dessa prática cultural, toma-se o registro, a conservação e a reprodução dessa atividade como parte importante de uma política de diversidade. Mais do que uma pretensa tentativa de repetição do passado, se coloca que o manuseio dos símbolos e dos lugares dessa cultura permitirá em alguma medida as transformações nas relações socioespaciais de um segmento da sociedade.

Nesse processo, tradição e modernidade parecem encontrar eixos de aproximação, pois as práticas artesanais, os valores antigos e as representações do passado podem ganhar novas áreas de influência. Os conhecimentos que haviam sido excluídos e substituídos por outros mais mecânicos e precisos podem então ser integrados ao mundo atual. Significa dizer que essa indústria cultural não pressupõe que a inovação se constitua pela via tecnológica, mas sim pelo know-howe pelo fortalecimento do vínculo entre produtor e consumidor.

Um exemplo dessa prática seria encontrado na proposta de criação de uma Região Cultural na América do Sul, relativa à cultura Mbyá-Guarani. Espalhada pelo Brasil, Bolívia, Paraguai e Argentina, a comunidade indígena Mbyá-Guarani vive em condição de emergência social. 
Suas práticas de sobrevivência baseadas em atividades de caça e coleta foram fortemente comprometidas pela expansão das fronteiras agrícolas e das atividades produtivas modernas. O aceite de uma tal proposta de Região Cultural significaria o reconhecimento por parte de instituições como o MERCOSUL da necessidade de apoio as suas práticas sustentáveis, como a apicultura e o artesanato, permitindo a esses grupos ganhar novas vias de interação socioeconômica. Também significaria a ampliação da base institucional de sua língua e de seus costumes, conferindo maior peso na região em questão. Em documento de 1995, o MERCOSUL já estabelecia esse compromisso nos seguintes termos: "Declarar o guarani como uma das línguas históricas do Mercosul e revalorizar seu legado cultural através da elaboração de um inventário de seu patrimônio, a promoção da pesquisa acadêmica e o ensino da língua" (1995). Aqueles conhecimentos tradicionais que teriam se mostrado incompatíveis com a sociedade moderna na visão dos Estados latino-americanos do século XX poderiam então ser convertidos em vias de entrada em um mundo globalizado no século XXI, alterando as relações de poder.

Para que essa via se realize, o desafio inicial é quebrar a busca de um tradicionalismo idealizado, quase imutável, e empoderar os grupos indígenas de forma que estes tenham plenas condições de alterar sua própria situação. Os resultados não podem ser completamente previstos e dependem de uma série de contatos culturais e econômicos que envolve respeito aos interesses locais, trocas e registros de conhecimentos. Se, em parte, foi a vulnerabilidade desse grupo étnico que manteve um modo de vida tradicional, alterar os poderes de tal grupo deve modificar as qualidades de suas representações. Isso problematiza os limites das políticas de patrimonialização observadas em diferentes países, que buscam a autenticidade como valor absoluto.

O último modelo a ser colocado aqui se refere à indústria cultural como lugar da inovação. Para que a produção de cultura se organize de modo a gerar novos produtos e/ou ideias, invariavelmentes e estabelece um padrão concentrado para a localização de serviços, de atividades de formação e de produção, tal como foi discutido no primeiro modelo. No entanto, algumas distinções são possíveis. No que se refere ao lugar da inovação, é preciso considerar que o produto cultural (ou o produto que recebe valores culturais) precisa de um longo período de testes e de materiais para se realizar, exigindo que o seu valor final seja mais elevado e também que as empresas que o criam tenham mais capital para investir. 
Paralelamente, é preciso que a inovação consiga, de alguma forma, manter valores ou formas que criaram a confiança na marca ao mesmo tempo em que adapta valores ou ideias da sociedade que podem alterar significativamente o produto final. Para tanto, o ciclo de Pesquisa e Desenvolvimento se mostra decisivo, indo além dos laboratórios: é preciso buscar nas pesquisas de mercado os valores e ideias que podem facilitar o processo de inovação. Criar algo novo sem essa base de dados, através da simples imaginação de alguns técnicos que, nos termos de Adorno, seriam os geradores da realidade, seria caro, difícil e pouco eficiente como estratégia.

Das trocas resultantes da proximidade existente entre essas diferentes atividades, criam-se continuamente novas formas ou novas representações do mundo atual. Aos poucos, uma referida área se torna um polo de produção de outros padrões culturais, ainda que, por vezes, a cadeia produtiva possa não estar completamente localizada no entorno do lugar da inovação. Com isso, o que conferiria individualidade a esse modelo seria justamente perceber que a interconexão de usos, de ensino e de produção de cultura permite o refinamento das atividades culturais como um todo, assim como a criação de uma marca que qualifica o espaço. Dito de forma mais simples e direta, inovar no plano cultural significa, muitas vezes, canalizar as conexões entre conhecimentos e práticas por intermédio do espaço. Nas palavras de Gertler:

Para atender ou adaptar as demandas de mercado que mudam rapidamente, e em um ambiente competitivo no qual os ciclos de vida dos produtos tornaram-se dramaticamente mais curtos, ganhou extrema importância o ônus que recai sobre as empresas para conseguirem inovações bem-sucedidas em produtos e processos. [...] Em vez do antigo modelo linear de inovação, [...] o novo modelo era interativo e recursivo (2010: p.48-49).

De acordo com a obra de Scott (1997), mais do que a presença de amplos parques industriais e a manutenção de máquinas e de um enorme grupo de trabalhadores não especializados, o modelo de uma indústria cultural focado na busca da inovação estabelece projetos mais criativos, trabalhadores com maior nível de formação, com menor hierarquia formal e origens variadas de recursos (fontes públicas e privadas associadas). Nesse processo, o foco da produção se encontra no conhecimento em si, nas alterações das cadeias produtivas, nas novas patentes e tendências, e nem tanto nos produtos criados em 
série. Como conclusão, o lugar da inovação poderia definir uma grande rede de lugares subordinado as suas criações, tal qual se desenvolve no Vale do Silício.

Para Saxenian, o sinal distintivo da inovação encontrada no Vale do Silício foi justamente uma dinâmica comunitária voltada para a criação, no qual informações, ideias, capitais e projetos circulavam de forma mais intensa do que normalmente ocorria em outros setores econômicos. O tempo que era dividido entre técnicos e gestores fora do ambiente de trabalho permitia igualmente ampliar a visão do produto e da sociedade como um todo. Em suas palavras:

Drawn together by the challenge of geographic and technological frontiers, the pioneers created a technical culture that transcended firm and function. They developed less formal social relationships and collaborative traditions that supported experimentation. They created firms that were organized as loosely linked confederations of engineering teams. Without intending so, Silicon Valley's engineers and entrepreneurs were creating a more flexible industrial system, one organized around the region and its professional and technical networks rather than around the individual firm (1994: p.30).

\section{CONSIDERAÇÕES FINAIS}

Esse artigo procurou apresentar os limites teóricos e metodológicos para a utilização da ideia de indústria cultural na Geografia contemporânea. Ao fazê-lo, negamos um conjunto de oposições binárias que são frequentemente usadas em nossa ciência: tradição-inovação, cultura-civilização, cultura-economia, abstrato-concreto e identidade-produção. Também problematizamos visões retiradas de modelos clássicos da produção e do consumo de cultura através da ideia de indústria cultural, pois as formas de avaliar as propriedades das redes urbanas, da estrutura interna das cidades, da economia em nuvem, das identidades e da comunicação e representação parecem se alterar significativamente. De uma forma geral, salientamos que a noção de indústria cultural pode ser observada além do julgamento de valor abstrato negativo criado por Adorno e repetido por um amplo conjunto de geógrafos, no qual o espaço é apenas um reflexo negativo da padronização econômica, sem qualquer tipo de força explicativa quanto ao real.

Os modelos apresentados como bases para o desenvolvimento do tema das indústrias culturais dentro da Geografia partem de diferentes combinações entre cultura, economia e política. Em alguns casos, trata-se de uma coordenação de interesses público-privados de 
ordem econômica, ao estabelecer as vantagens para ambos por uma localidade concentrada. Em outros momentos, se constituía pelo referenciamento cultural de causas políticas, permitindo assim que os símbolos difundidos pudessem servir de base para novas formas de se definir relações de poder em relação ao território. Em outros modelos, a combinação entre cultura e economia nos permitiria dotar os produtos finais de valores mais variados do que a simples defesa da técnica, muitos destes valores tomados por intermédio de um olhar lançado sobre o espaço, tornando a atividade de consumir em um estilo de vida para o indivíduo.

A difusão dos produtos de tais indústrias culturais se insere então em duas novas necessidades para a renovação dos temas de estudo da Geografia: a primeira é entender a difusão de produtos culturais além dos limites da escala local e do alcance de sua identidade-matriz, exigindo que as trocas culturais sejam pensadas como base inevitável para a organização espacial; segundo, a concepção de que as atividades produtivas não dependem da irracionalidade do consumidor e nem tampouco do seu total controle pela redução da capacidade cognitiva (ou simples manipulação) dos indivíduos - do ponto de vista da produção econômica de bens culturais, seria preciso reforçar o referencia mento cultural da produção e, assim, aproximar a relação entre produtor e consumidor.

Dessa forma, as indústrias culturais se mostrariam como legítimos objetos de estudo da Geografia na medida em que fosse possível refletir sobre a maneira como o território é produzido, organizado, representado e mobilizado para fins variados, conectando cultura, política e economia em um certo arranjo. Ainda que tais indústrias culturais não representem o surgimento de um processo produtivo que reduza as contradições do sistema capitalista ou ofereça soluções para conflitos sociais, estas apresentam novas formas de intervenção no espaço e, por consequência, se mostram objetos legítimos do conhecimento geográfico.

\section{BIBLIOGRAFIA}

ADORNO, T.W; HORCKEIHEIMER, M. Indústria cultural e sociedade. São Paulo: Paz e Terra, 2002.70p.

AFROREGGAE. Disponível em: <http://www.afroreggae.org.br/>. [20/04/2012]. 
ALVES, E. Cultura presta contas - Primeira Audiência Pública do Fundo Municipal de Cultura de Paulínia $\quad$ - $\quad 2009.2$ Disponível em: <http://www.culturapaulinia.com.br/culturapaulinia/arquivos/audiencias/audiencia.pdf> [18/04/2012].

AMIN, A; THRIFT, N. Cultural-economy and cities. Progress in Human Geography, 2007,vol. 31, no 2, p. 143-161.

BOLIVIA. Cultural. In: Plano Nacional de Desarrollo (2006). Disponível em: <http://www.sicsur.org/archivos/documentos/bolivia_plan_nacional_desarrollo_capitulo_c ultural.pdf>. [18/04/2012].

CASTREE, N. Economy and culture are dead! Long live economy and culture!. Progress in Human Geography, 2004,no 28, p. 204-226.

CORRÊA, R.L. Estudos Sobre a Rede Urbana. Rio de Janeiro: Bertrand Brasil, 2006. 336p.

COSGROVE, D.; JACKSON, P.New directions in cultural geography In: Area, 1987,no 19, p.95101.

GERTLER, M. Uma geografia econômica cultural da produção. In: CORRÊA, R.L.; Rosendahl, Z. (org.) Economia, cultura e espaço. Rio de Janeiro: EdUERJ, 2010, pp. 37-97.

GIBSON, C. Cultures at work: why 'culture' matters in research on the 'cultural' industries. Social \& Cultural Geography, 2003, Volume 4, Issue 2, p. 201-215.

GIBSON, C.; KONG, L. Cultural economy: a critical review. Progress in Human Geography, 2005, vol. 29, no5, p. 541-561.

HABERMAS, J. The Philosophical Discourse of Modernity: Twelve Lectures. Cambridge: Polity Press, 1987. 450p.

HARTSHORNE, R. The nature of geography. Chicago: Annals of the Association of American Geographers, 1939.482p.

HARVEY, D. A condição pós-moderna. São Paulo: Loyola, 1993.349p.

JACKSON, P. Rematerializing social and cultural geography. Social \& Cultural Geography, 2000, Vol. 1, no. 1, p. 9-14.

LESLIE, D. Consumer subjectivity, space, and advertising research. Environment and Planning A, 1999, volume 31, p. $1443-1457$.

MERCOSUL. "Ata de Assunção - Segunda reunião especializada de cultura - 02/95". Disponível em:<http://blogs.cultura.gov.br/mercosur/files/2007/05/ata-de-assuncaomercosul-segunda-reuniao-especializada-de-cultura-ata-02-95 (3).doc>. [20/04/2012].

MITCHELL, D. There's no such thing as culture: towards a reconceptualization of the idea of culture in geography. Transactions - Institute of British Geographers, 1995,no 20, p. 102116.

POWER, D.; SCOTT, A.J. Cultural industries and the production of culture. London: Routledge, 2004.384p.

PRATT, A.C.; The Cultural Economy: A Call for Spatialized 'Production of Culture' Perspectives. International Journal of Cultural Studies, 2004, vol. 7, no 1, p. 117-128.

PRATT, A.C. The cultural industries: the case of new media in world cities. Cultural Economics, 1999, vol. 1, no 4, p. 1-10.

PRATT, A.C. The cultural industries production system: a case study ofemployment change in Britain, 1984-1991. Environment and Planning A, 1997, no 29, p. 1953-1974. 
REIMER, S. Geographies of production III: knowledge, cultural economies and work. Progress in Human Geography, 2009,vol. 33, no 5, p. 677-684.

SANTOS, Milton. Por uma outra globalização - Do pensamento único à consciência universal. Rio de Janeiro: Record, 2000. 174p.

SAXENIAN, A. Regional advantage: Culture and competition in Silicon Valley and Route 128.Cambridge: Harvard University Press, 1994.240p.

SCOTT, A.J.; De la Silicon Valley à Hollywood: croissance et développement de l'industrie multimédia en California. Espaces et Sociétés, 1997, no 88-89, p. 15-51.

SCOTT, A.J. The cultural economy of cities - Essays on the geography of image-producing industries. London: Sage, 2000.245p.

SENNETT, R. O declínio do homem público - as tiranias da intimidade. São Paulo: Companhia das Letras, 1989.448p.

TREMBLAY, D.G.; ROUSSEAU, S. The Montreal Multimedia Sector: A Cluster, a New Mode of Governance or a Simple Co-location? Canadian Journal of Regional Science, 2005, nํ28, v.2, p.299-327.

VALVERDE, R.R.H.F. Espace et publicité: les interactions entre la marque et la ville. Géographie et Cultures, 2010, v. 73, p. 1-14.

\begin{tabular}{r|r|}
$\begin{array}{r}\text { Artigo submetido em } \\
\text { Artigo aceito em }\end{array}$ 03/03/2015 \\
\hline
\end{tabular}

